\title{
Interference between surgical magnetic drapes and pacemakers: an observational study comparing commercially available devices and a new magnetically isolated drape
}

\author{
Valerie Zaphiratos ${ }^{1 *} \mathbb{D}$, Hubert Chiasson ${ }^{2}$, Pierre Drolet ${ }^{1}$, Bruno Benzaquen ${ }^{3}$, Jacques Lapointe ${ }^{3}$ \\ and Louis-Philippe Fortier ${ }^{1}$
}

\section{${ }^{*}$ Correspondence:}

valerie@zaphiratos.ca

${ }^{1}$ Department of Anesthesia,

Maisonneuve-Rosemont

Hospital, University

of Montreal, 5415 Boul. de

L'Assomption, Montreal, QC

H1T 2M4, Canada

Full list of author information

is available at the end of the article

\begin{abstract}
Background: Magnetic fields may potentially interfere with the function of cardiovascular implantable electronic devices. Sterile magnetic drapes used to hold surgical instruments are often placed on the patient's thorax, and they are likely to interfere with the function of these devices.
\end{abstract}

Methods: Thirty patients were recruited to compare a new prototype surgical magnetic drape ( $\mathrm{LT} 10 \mathrm{G}^{\mathrm{TM}}$ by Menodys) made with bottom-isolated ferrite magnets to the Covidien magnetic drape we used in a previous study. Twenty additional patients were recruited to compare the prototype drape with four commercially available surgical magnetic drapes.

Results: Magnetic interference was found in 33 of the 50 total patients (70\%) when the Covidien drape was placed over the pacemaker. Of the 20 additional patients, 5 patients (25\%) displayed magnetic interference with a second type of surgical magnetic drape. A third magnetic drape caused interference in one patient (5\%), whereas a larger drape of the same model did not interfere in any patient. No patients demonstrated magnetic interference with the prototype drape.

Conclusion: Bottom isolation of magnets in the prototype magnetic drape $\left(\mathrm{LT} 10 \mathrm{G}^{\mathrm{TM}}\right)$ used during surgery prevents magnetic interference in all patients when placed over the pacemaker. Three of the four commercially available magnetic drapes tested demonstrated magnetic interference. Flipping the prototype drape is not recommended as it may expose non-isolated magnets to the cardiovascular implantable electronic device.

Keywords: Pacemaker, CIED, Magnet, Interference, Drape, Mat

\section{Background}

Over 1 million pacemakers and over 320,000 implantable cardioverter-defibrillators (ICDs) were implanted worldwide in 2009, and the implantation of cardiovascular implantable electronic devices (CIEDs) is on the rise [1-3]. Placing a magnet on a cardiac pacemaker usually enables an asynchronous mode in which the heart is paced at 
a predetermined frequency [4-7]. However, this magnet-activated asynchronous mode may have undesirable consequences, such as battery depletion, undesirable hemodynamic effects due to rapid pacing in some pacemakers, and rarely, ventricular dysrhythmias if pacemaker stimulation occurs in the vulnerable part of the cardiac cycle in patients with an intrinsic cardiac rhythm [4, 8-12]. In patients with an ICD, application of a magnet does not enable asynchronous pacing, but rather may suppress the detection of arrhythmias and prevents the device from delivering the appropriate therapy $[4-6,11,12]$.

Sterile magnetic drapes are commonly used during surgery to hold metal instruments in the sterile field. The drape is often placed on the patient's thorax, the usual location for a CIED. The placement of a magnetic drape over a pacemaker has been reported to result in unintended tachycardia and cardiac arrest [13]. In a previous study [14], it was found that surgical magnetic drapes are likely to activate the magnetic switch and cause asynchronous pacing in most patients when placed over the pacemaker. The magnetic drape tested in that study contained 70 ceramic ferrite magnets (116 Reusable Drape \#31140588, Devon by Covidien, Mansfield, MA, USA). According to manufacturer's specifications, over 5-10 Gauss is required to enable the asynchronous mode in the pacemakers tested in that study [14], a level reached when one of the 70 ferrite magnets from the drape is $3.4 \mathrm{~cm}$ away from the generator. There are several ways to reduce the magnetism of the drape, including alternating the polarities of adjacent magnets, or adding an isolating material between the magnet and the pacemaker.

Therefore, the purpose of this study was twofold. First, to compare the interference generated by the magnetic drape from Covidien used in a previous study [14] with a prototype magnetic drape manufactured with bottom-isolated ferrite magnets, currently commercialized as the $\mathrm{LT} 10 \mathrm{G}^{\mathrm{TM}}$ by Menodys since September 2014, in order to determine in patients with a cardiac pacemaker whether asynchronous mode behavior develops. The second part of our study compares four different commercially available surgical magnetic drapes with the prototype drape containing bottom-isolated ferrite magnets. Our hypothesis is that placement of commercially available surgical magnetic drapes may result in asynchronous pacing in pacemaker patients, whereas the prototype magnetic drape with bottom-isolated ferrite magnets will not cause asynchronous pacing in these same patients.

\section{Methods}

Following approval of the research ethics committee of the Maisonneuve-Rosemont Hospital affiliated to the University of Montreal, patients with an implanted cardiac pacemaker (Medtronic, Minneapolis, Minnesota, and Boston Scientific, Natick, MA, USA) were recruited for this study from October 2011 until November 2011 during regular device follow-up visits at the outpatient pacemaker clinic. After the cardiologist performed the initial scheduled device interrogation, the protocol was explained to all patients, and those who agreed to participate in the study, signed a written consent form.

Patient data including age, sex, height, weight, body mass index (BMI) were recorded. The protocol was performed with the patient supine, wearing a hospital gown. Continuous 3-lead electrocardiographic (ECG) monitoring was placed on the patient and the ECG was analysed by a medical Doctor (MD), an anesthesiologist or an anesthesiology 
senior resident, as well as a registered Nurse (RN) throughout the study. First, a strip of the patient's baseline rhythm was obtained. Then, a Medtronic round magnet (\#1741052, Minneapolis, MN, USA) was placed on the pacemaker and a copy of the ECG to confirm the magnet mode behavior as specified by the manufacturer was obtained. Patients with ICDs and patients in whom the magnet rate cardiac rhythm was indistinguishable from their baseline rhythm were excluded. The round magnet was then removed.

Part 1 of the study was to assess two different magnetic drapes. A member of the personnel not involved in the study concealed the two magnetic drapes in an opaque plastic bag. The first drape (“CVD”) measured $29.5 \mathrm{~cm} \times 37.5 \mathrm{~cm}$ and contained 70 ceramic ferrite magnets (116 Reusable Drape \#31140588, Devon by Covidien, Mansfield, MA, USA) (Fig. 1). In a previous study [14], the magnets in the CVD drape were found to be inserted in a random fashion, regardless of polarity. In a single drape, the polarity of each magnet can impact the overall vector of magnetism of that drape. Thus, at the beginning of each data collection day, a different CVD drape was used in order to reduce bias caused by the potential magnetic signature of each commercial drape. The second magnetic drape was a prototype made with a silicone shell similar to the CVD drape, but instead contained 70 isolated ferrite magnets (Fig. 2). The isolation material consisted of a steel-based metal cup that diminished the magnetic remanence on the patient side of the drape and only encapsulated the underside of each ferrite magnet in order to create a unidirectional magnetic field. The overall magnetic field on the patient facing side was less than 10 Gauss (Fig. 3) (Additional file 1).

Each magnetic drape was concealed and centered over the patient's pacemaker, with the help of a measuring tape, one after the other. The investigator performing the study and the data collector were both blinded to the type of magnetic drape. Magnetic interference was identified if the cardiac rhythm was asynchronous and identical to that produced by the round magnet rhythm. If there was no change in rhythm with the magnetic drape, the drape was displaced in 1-2 cm increments over the pacemaker in an effort

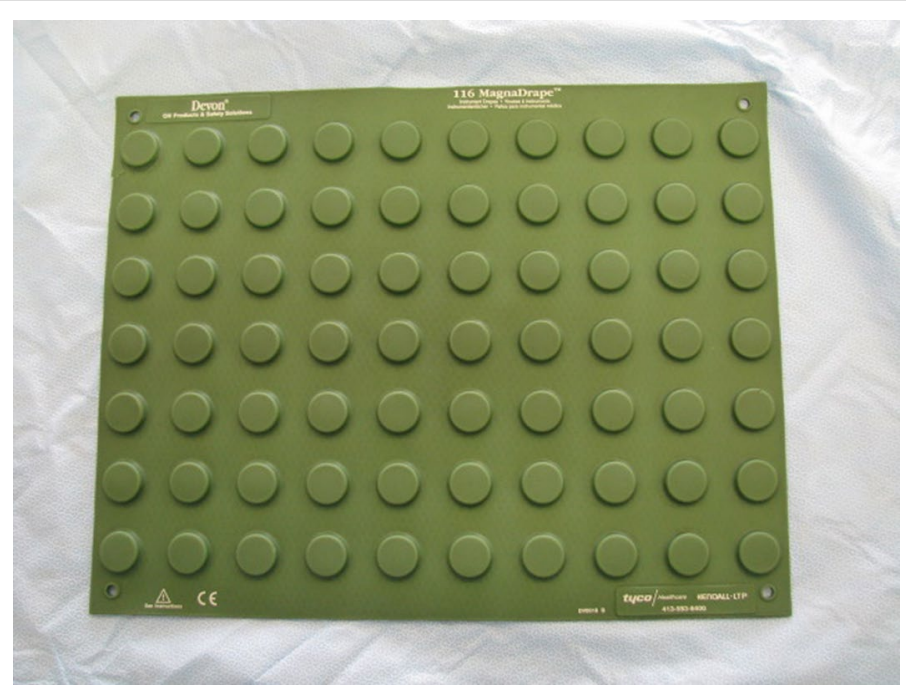

Fig. 1 CVD surgical magnetic drape containing 70 ceramic ferrite magnets 


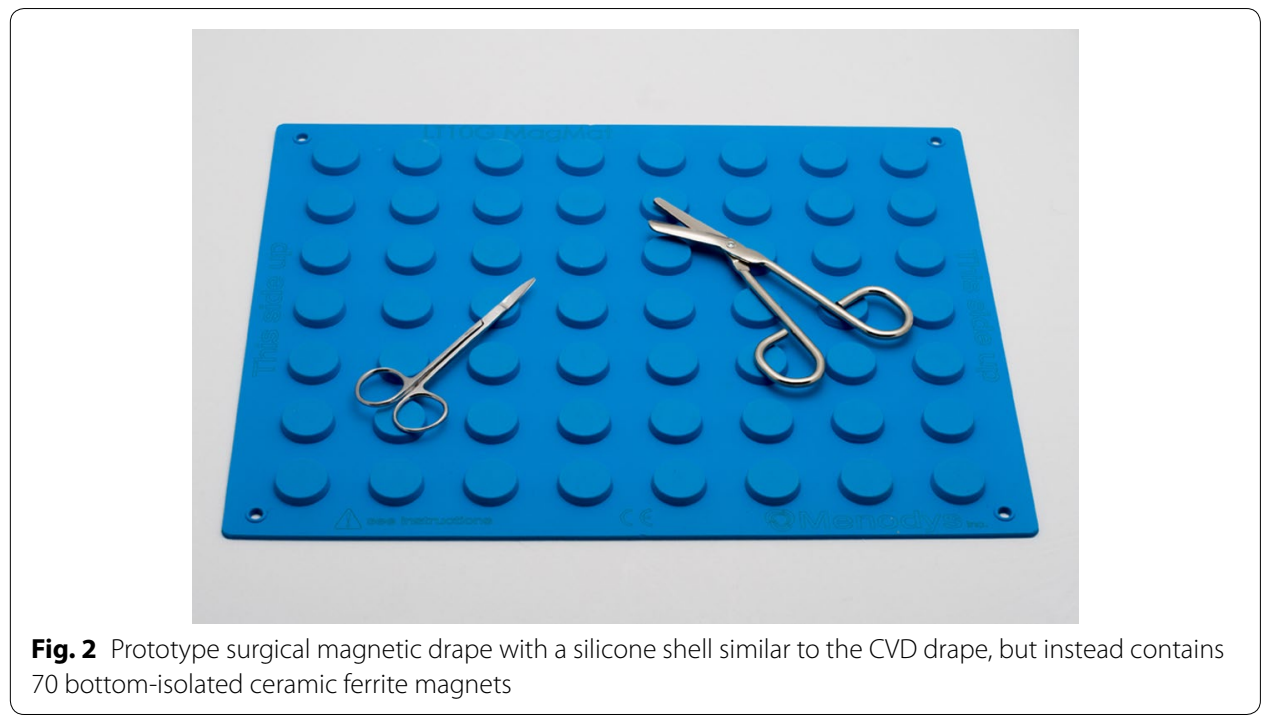

to elicit an asynchronous rhythm. Once the protocol was completed, the patient was referred to the cardiologist who, if the situation permitted, discharged the patient.

Part 2 of the study consisted of evaluating and comparing 4 different commercially available magnetic drapes, including the CVD, with the prototype magnetic drape. All four of these commercially available magnetic drapes underwent the same protocol as the magnetic drapes in part 1 of the study. Due to the different sizes and shapes of the four drapes, it was not possible to create a blinded evaluation with an opaque plastic bag. The magnetic drapes evaluated were the CVD magnetic drape, the "JCM" magnetic drape (Reusable Magnetic Pad, Jac-Cell Medic, Town of Mount-Royal, Quebec, Canada), the "LDR" magnetic drape (Magnetic Instrument Pad \#25-002, size 20" $\times 16^{\prime \prime}$, DeRoyal Industries Inc., Powell, TN, USA), and the "SDR" magnetic drape (Magnetic Instrument Pad \#25-001, size 10" $\times 16^{\prime \prime}$, DeRoyal Industries Inc., Powell, TN, USA).

The sample size calculation for the primary outcome (first part of the study) was based on the direct comparison between the proportion of patients experiencing pacemaker interference associated with the CVD drape in one group and the new prototype in the other. A previous study having shown that using the CVD drape caused pacemaker interference in $70 \%$ of participants [14], we elected to look for a $50 \%$ reduction (from 70 to $35 \%$ ) in interference with the prototype drape. It was then calculated that 30 patients per group were needed to show such a difference with alpha and beta errors of 0.05 and 0.8 respectively.

The sample size calculation for part 2 was to be derived from the results obtained during the first part of the study, using the proportion of patients experiencing interference with the prototype as a base for calculation. Since no case of interference was observed, it was arbitrarily decided to recruit twenty participants to provide an exploratory overview of the pacemaker interference associated with the various commercially available devices.

Fisher's exact test was used for comparisons in the first part of the study. Only descriptive statistics were used for the second part. Calculations and analyses were performed with Prism 5.0 statistical package (GraphPad Software Inc, La Jolla, CA, USA). Unless 


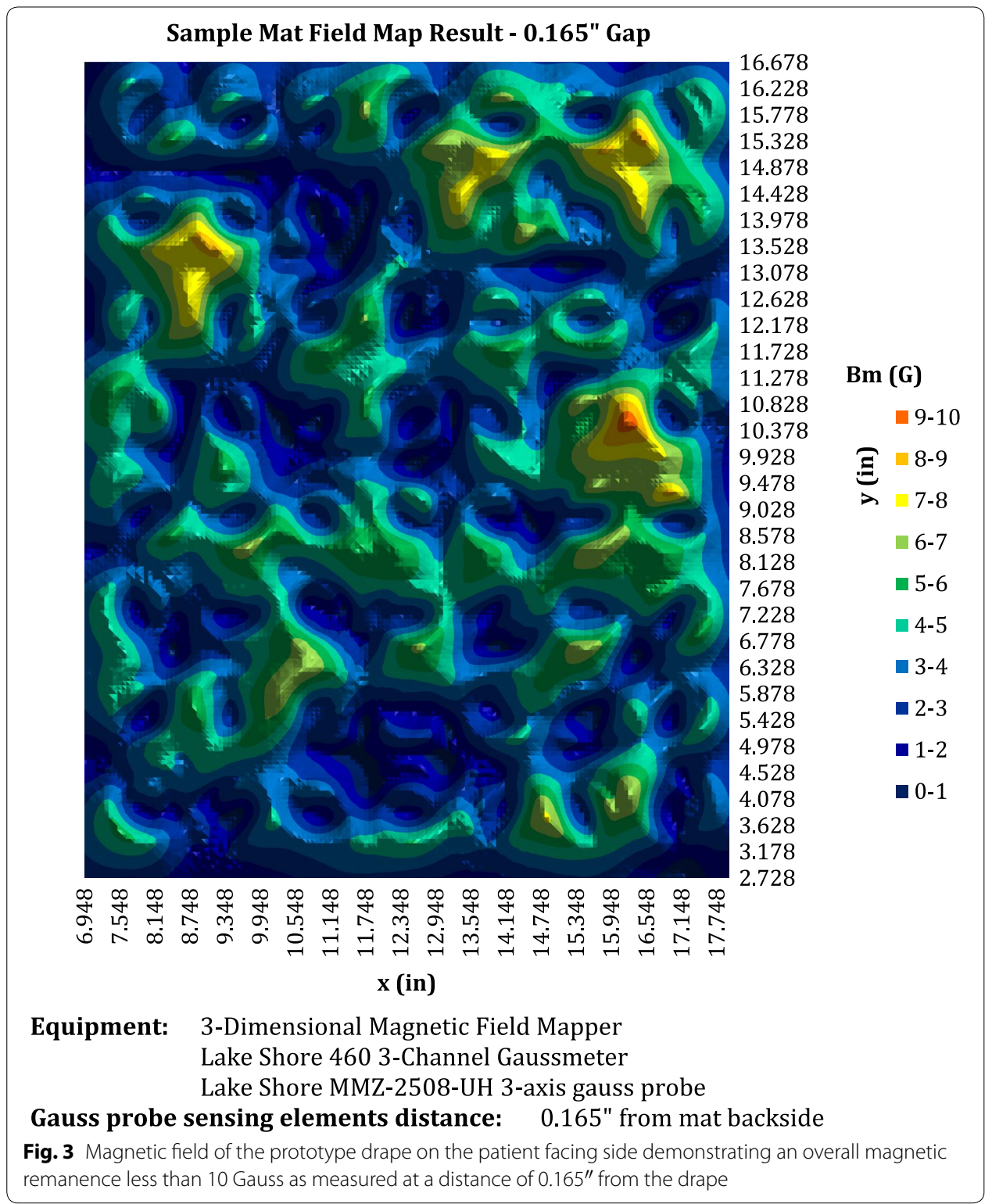

stated otherwise, data are presented as mean $\pm \mathrm{SD}$ and a $p$ value $<0.05$ was deemed significant.

\section{Results}

Demographic criteria of the patients for both parts of the study are listed in Table 1 . Thirty patients were recruited in part 1 , and three were excluded due to a clerical mistake in the make and model of magnetic drape that had been placed in the opaque plastic bag. Of the 27 patients studied, 17 had a Boston Scientific pacemaker and 10 patients had a Medtronic pacemaker. All pacemakers were placed subcutaneously. Seventeen patients $(63 \%)$ displayed asynchronous cardiac pacing when the CVD drape was placed over the pacemaker, whereas none of the patients displayed magnetic interference with the prototype drape $(p<0.0001)$ (Table 2$)$. 
In part 2 of the study, 20 patients were recruited and studied. Nine had a Boston Scientific pacemaker and 11 patients had a Medtronic pacemaker. All pacemakers were placed subcutaneously. Sixteen patients (80\%) demonstrated asynchronous cardiac pacing with the CVD drape. For the JCM magnetic drape, 5 patients (25\%) displayed asynchronous cardiac pacing. The LDR magnetic drape did not cause asynchronous cardiac pacing in any patient. The unfolded SDR drape displayed asynchronous cardiac pacing in 1 patient (5\%). No patients demonstrated asynchronous cardiac pacing with the prototype drape. No patients exhibited any adverse outcomes during the study (Table 3). Detailed results for each patient are available in Appendix.

\section{Discussion}

The findings in this study suggest that bottom-isolation of the magnets in an unfolded magnetic drape used during surgery prevents asynchronous pacing in all patients when placed over the pacemaker. Three of the four commercially available magnetic drapes tested demonstrated asynchronous cardiac pacing.

For both parts of this study, the CVD drape caused asynchronous pacing in a total of 33 patients (70\%). These results mirror a previous study [14] where $70 \%$ of patients demonstrated asynchronous rhythm with the CVD magnetic drape. Although the JCM magnetic drape caused asynchronous pacing in $25 \%$ of patients, this is less than that of the CVD magnetic drape. This is possibly due to the fact that the magnets of the JCM drape are placed further apart creating a weaker magnetic field compared to those in the CVD. Since we did not test the remanence of the individual magnets in each of the commercially available magnetic drapes in this study, we cannot postulate on the strength of their remanence compared to the magnets in the CVD.

Among the other commercially available drapes, the LDR magnetic drape did not exhibit magnetic pacemaker interference. Considering the LDR magnetic drape is of the same make and model as the SDR drape, but simply $10^{\prime \prime}$ larger, it is possible that our sample size of 20 patients was not adequate to elicit asynchronous rhythm with the LDR drape. In a previous study [14], it was suggested that a single well-positioned magnet can induce asynchronous rhythm. Thus, it is possible that the position of the magnets in the SDR drape we tested created a stronger magnetic field than those of that particular LDR drape. This may no longer be true when switching for another identical LDR or SDR drape of the same make and model. Unfortunately, we did not test for this in our study. Contrary to the CVD and JCM drapes, the LDR and SDR drapes are disposable, and it is possible that the remanence of the disposable drapes may be lesser or may

Table 1 Demographic data

\begin{tabular}{|c|c|c|}
\hline Demographic & Part 1 & Part 2 \\
\hline Patients & $N=27$ & $N=20$ \\
\hline Gender & M 15:F 12 & M 10:F 10 \\
\hline Age (years) (mean $\pm S D$ ) & $79 \pm 8$ & $78 \pm 8$ \\
\hline Height (m) (mean \pm SD) & $1.67 \pm 0.07$ & $1.66 \pm 0.09$ \\
\hline Weight $(\mathrm{kg})$ (mean $\pm \mathrm{SD})$ & $75 \pm 17.6$ & $73 \pm 16$ \\
\hline Body mass index $\left(\mathrm{kg} / \mathrm{m}^{2}\right)($ mean $\pm \mathrm{SD})$ & $27 \pm 5.2$ & $27 \pm 4$ \\
\hline Type of pacemaker (Boston Scientific/Medtronic) & $17 / 10$ & $9 / 11$ \\
\hline
\end{tabular}


Table 2 Results from Part 1 of the study $(n=27)$

\begin{tabular}{lll}
\hline & \multicolumn{2}{l}{ Asynchronous rhythm } \\
\cline { 2 - 3 } \cline { 3 - 3 } & CVD drape & Prototype drape \\
\hline Patients (\%) & $\mathrm{N}=17(63 \%)$ & $\mathrm{N}=0$ \\
Age (years) (mean $\pm \mathrm{SD})$ & $81 \pm 6$ & $\mathrm{~N} / \mathrm{A}$ \\
Gender & $\mathrm{M} 11 / \mathrm{F} 6$ & $\mathrm{~N} / \mathrm{A}$ \\
Weight $(\mathrm{kg})($ mean $\pm \mathrm{SD})$ & $74 \pm 18$ & $\mathrm{~N} / \mathrm{A}$ \\
Height $(\mathrm{m})($ mean $\pm \mathrm{SD})$ & $1.68 \pm 0.07$ & $\mathrm{~N} / \mathrm{A}$ \\
Body mass index $\left(\mathrm{kg} / \mathrm{m}^{2}\right)($ mean $\pm \mathrm{SD})$ & $26 \pm 5$ & $\mathrm{~N} / \mathrm{A}$ \\
Pacemaker (Boston Scientific/Medtronic) & $7 / 10$ & $\mathrm{~N} / \mathrm{A}$ \\
\hline
\end{tabular}

Table 3 Results from part 2 of the study $(n=20)$

\begin{tabular}{|c|c|c|c|c|c|}
\hline Drapes tested & Prototype & CVD & JCM & SDR & LDR \\
\hline $\begin{array}{l}\text { Patients who demonstrated asynchronous } \\
\text { rhythm (\%) }\end{array}$ & $N=0$ & $N=16(80 \%)$ & $\mathrm{N}=5(25 \%)$ & $N=1(5 \%)$ & $N=0$ \\
\hline Age (years) (mean \pm SD) & $\mathrm{N} / \mathrm{A}$ & $80 \pm 7$ & $82 \pm 7$ & 87 & $\mathrm{~N} / \mathrm{A}$ \\
\hline Gender & $\mathrm{N} / \mathrm{A}$ & $M 7 / F 9$ & M 4/F 1 & M O/F 1 & $\mathrm{~N} / \mathrm{A}$ \\
\hline Weight (kg) (mean \pm SD) & $\mathrm{N} / \mathrm{A}$ & $69 \pm 15$ & $70 \pm 18$ & 44 & $\mathrm{~N} / \mathrm{A}$ \\
\hline Height $(m)($ mean \pm SD) & $\mathrm{N} / \mathrm{A}$ & $1.66 \pm 0.09$ & $1.74 \pm 0.08$ & 1.52 & $\mathrm{~N} / \mathrm{A}$ \\
\hline Body mass index $\left(\mathrm{kg} / \mathrm{m}^{2}\right)($ mean $\pm \mathrm{SD})$ & $\mathrm{N} / \mathrm{A}$ & $26 \pm 4$ & $26 \pm 3$ & 19 & N/A \\
\hline Pacemaker (Boston Scientific/Medtronic) & $\mathrm{N} / \mathrm{A}$ & $6 / 10$ & $3 / 2$ & $0 / 1$ & $\mathrm{~N} / \mathrm{A}$ \\
\hline
\end{tabular}

have diminished during the study period, as they are meant for single use only. From our results, it is reasonable to propose that at least a subset of the magnetic drapes produced by this company may generate magnetic interference with pacemakers.

The prototype magnetic drape, currently commercialized as the $\mathrm{LT} 10 \mathrm{G}^{\mathrm{TM}}$ by Menodys, is manufactured to diminish the magnetic remanence on the patient facing side of the drape. This is achieved by having each individual magnet of the drape encapsulated in a cup with a steel-based metal isolation material. Due to this technology, no patient in our study demonstrated an asynchronous cardiac rhythm with the LT10G ${ }^{\mathrm{TM}}$ magnetic drape.

\section{Limitations}

Our study was limited to the magnetic drapes and pacemakers tested. Thus, our results may not apply to all commercially available magnetic drapes and pacemakers. In addition, our sample size for the second part of our study was arbitrarily determined and may warrant further investigation with more patients and different types of magnetic drapes and pacemakers.

Few studies have described the risk of interference between magnets and CIEDs, and only one study has specifically examined magnetic surgical drapes and it demonstrated that the unfolded CVD magnetic drape caused asynchronous rhythm in $70 \%$ of patients [14]. In addition, the authors describe that magnetic interference decreases markedly with increasing caudal distance from the pacemaker. Other studies describe the risk of interference between magnets and CIEDs. Ryf et al. [15]. demonstrated in an in vitro study that different neodymium magnets found in everyday life, such as in toys and jewelry can all activate asynchronous pacing modes in pacemakers when placed at various distances from the device. Magnetic interference with different neodymium magnets 
occurred when placed up to $3 \mathrm{~cm}$ to the device [16]. Prolonged exposure to similar magnets were implicated in intermittent, erratic behavior of an ICD [17] and deactivation of an ICD resulting in a fatal consequence [18]. In a clinical study by Hiller et al. [19], three of 12 patients with a pacemaker experienced interference by small dental mini-magnets. The effect disappeared once the magnets were pulled $1 \mathrm{~cm}$ away.

\section{Conclusion}

Commercially available surgical magnetic drapes may result in asynchronous pacing. Three of the four commercially available magnetic drapes tested demonstrated magnetic interference. The prototype magnetic drape with bottom-isolated ferrite magnets tested in our study did not cause asynchronous pacing in these same patients. This new technology has the potential to enhance the safety of the operating room environment for patients with CIEDs. Flipping the prototype drape is not recommended as it may expose non-isolated magnets to the CIED.

\section{Additional file}

Additional file 1. Patent for the LT10G'M drape from Menodys: US patent 9,232,976. Dated January 12th, 2016. http://patft.uspto.gov/netacgi/nph-Parser?Sect1=PTO1\&Sect2=HITOFF\&d=PALL\&p=1\&u=\%2Fnetahtml\%2FPTO\%2 Fsrchnum.htm\&r=1\&f=G\&l=50\&s1=9232976.PN.\&OS=PN/9232976\&RS=PN/9232976.

\section{Abbreviations}

ICD: implantable cardioverter-defibrillator; CIED: cardiovascular implantable electronic device; BMI: body mass index; ECG: electrocardiogram; MD: Medical Doctor; RN: registered Nurse; CVD: Devon by Covidien drape; JCM: Jac-Cell medic drape; LDR: DeRoyal Industries Inc. drape, size 20" × 16"; SDR: DeRoyal Industries Inc. drape, size 10" × 16".

\section{Authors' contributions}

VZ designed and conducted the study, analysed the data, and was the primary writer of the manuscript. HC designed the study, was the primary conductor of the study, analysed the data, and helped write the manuscript. PD analysed the data, and helped write the manuscript. BB and JL designed and conducted the study. LPF designed the study, analysed the data, and helped write the manuscript. All authors read and approved the final manuscript.

\section{Author details}

${ }^{1}$ Department of Anesthesia, Maisonneuve-Rosemont Hospital, University of Montreal, 5415 Boul. de L'Assomption, Montreal, QC H1T 2M4, Canada. ${ }^{2}$ Department of Anesthesia, Grand-Portage regional Hospital, Riviere-du-Loup, QC, Canada.

${ }^{3}$ Department of Cardiology, Maisonneuve-Rosemont Hospital, University of Montreal, Montreal, QC, Canada.

\section{Acknowledgements}

We gratefully acknowledge Nadia Godin RN, anesthesia research assistant at Maisonneuve-Rosemont hospital, for her substantial contribution to patient recruitment and data acquisition.

\section{Competing interests}

Dr. Valerie Zaphiratos and Dr. Louis-Philippe Fortier hold a patent for magnetic shielding of surgical magnetic drapes (US 9,232,976, CA 2803194, EP 2584993, WO 2011160236) and are co-founders of a surgical magnetic drape that is safer for patients with cardiovascular implantable electronic devices such as pacemakers. The prototype drape used in this study is currently commercialised as the LT10G ${ }^{\mathrm{TM}}$ by Menodys in North America and Europe since September 2014. VZ and LPF receive royalties associated with the sale of the $\mathrm{LT}_{10 \mathrm{G}^{\mathrm{TM}}}$ drape due to their part ownership of the patent.

\section{Availability of data and supporting materials}

See Additional file 1.

\section{Funding}

The CVD and JCM drapes were provided by Maisonneuve-Rosemont hospital, as these were the drapes that were routinely used in the operating room at the time of the study. A case of disposable LDR and SDR drapes were purchased by Maisonneuve-Rosemont hospital from DeRoyal Industries Inc. A sample of each drape was provided to us from Maisonneuve-Rosemont hospital for the study. There was no funding to complete the study.

\section{Appendix}

See Tables 4 and 5. 


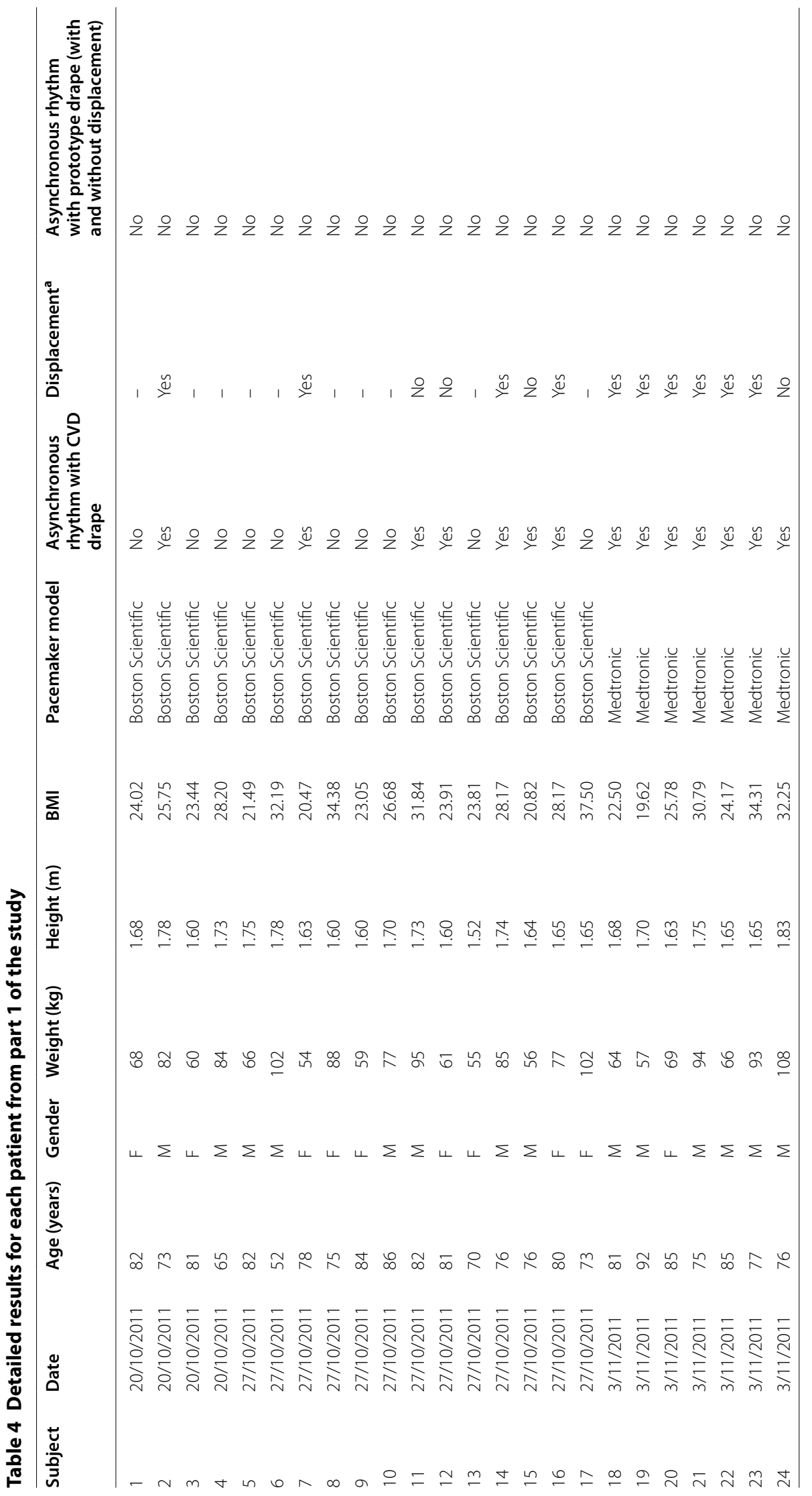




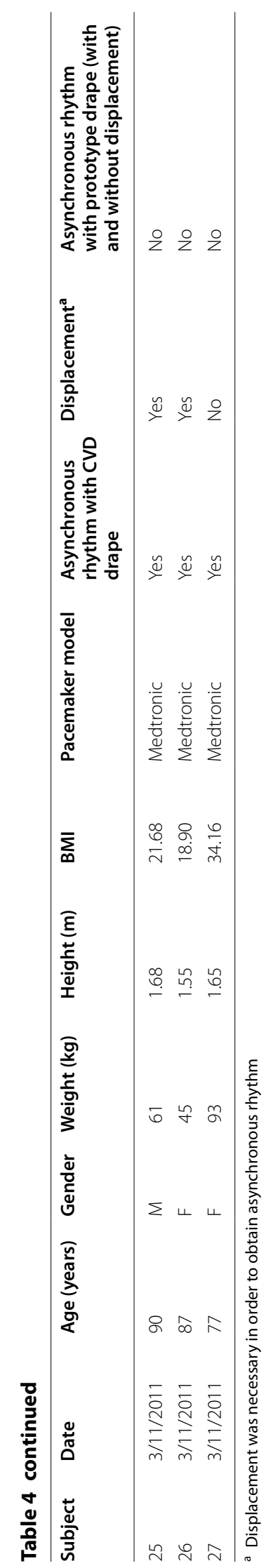


Table 5 Detailed results for each patient for part 2 of the study

\begin{tabular}{|c|c|c|c|c|c|c|c|c|c|c|c|}
\hline \multirow[t]{2}{*}{ Subject } & \multirow[t]{2}{*}{ Age } & \multirow[t]{2}{*}{ Gender } & \multirow{2}{*}{$\begin{array}{l}\text { Weight } \\
\text { (kg) }\end{array}$} & \multirow{2}{*}{$\begin{array}{l}\text { Height } \\
\text { (m) }\end{array}$} & \multirow[t]{2}{*}{ BMI } & \multirow{2}{*}{$\begin{array}{l}\text { Pacemaker } \\
\text { model }\end{array}$} & \multicolumn{5}{|c|}{ Asynchronous rhythm with drape } \\
\hline & & & & & & & Prototype & JCM & LDR & SDR & CVD \\
\hline 1 & 74 & M & 89 & 1.78 & 28.1 & Medtronic & No & No & No & No & No \\
\hline 2 & 87 & $\mathrm{~F}$ & 44 & 1.52 & 19 & Medtronic & No & No & No & Yes & Yes \\
\hline 3 & 66 & M & 89 & 1.73 & 29.7 & Medtronic & No & No & No & No & Yes \\
\hline 4 & 78 & M & 70 & 1.70 & 24.2 & Medtronic & No & No & No & No & Yes \\
\hline 5 & 86 & $\mathrm{~F}$ & 52 & 1.60 & 20.3 & Medtronic & No & No & No & No & Yes \\
\hline 6 & 87 & F & 66 & 1.55 & 27.5 & Medtronic & No & No & No & No & Yes \\
\hline 7 & 88 & $\mathrm{~F}$ & 61 & 1.65 & 22.4 & Medtronic & No & No & No & No & Yes \\
\hline 8 & 81 & M & 77 & 1.80 & 23.8 & Medtronic & No & Yes & No & No & Yes \\
\hline 9 & 69 & M & 80 & 1.60 & 31.2 & $\begin{array}{l}\text { Boston } \\
\text { Scientific }\end{array}$ & No & No & No & No & No \\
\hline 10 & 75 & M & 60 & 1,49 & 28.6 & $\begin{array}{l}\text { Boston } \\
\text { Scientific }\end{array}$ & No & Yes & No & No & Yes \\
\hline 11 & 64 & $\mathrm{~F}$ & 94 & 1.60 & 36.7 & $\begin{array}{l}\text { Boston } \\
\text { Scientific }\end{array}$ & No & No & No & No & No \\
\hline 12 & 92 & $\mathrm{~F}$ & 46 & 1,49 & 21.9 & $\begin{array}{l}\text { Boston } \\
\text { Scientific }\end{array}$ & No & Yes & No & No & Yes \\
\hline 13 & 78 & $\mathrm{~F}$ & 89 & 1.70 & 30.8 & $\begin{array}{l}\text { Boston } \\
\text { Scientific }\end{array}$ & No & No & No & No & Yes \\
\hline 14 & 76 & M & 91 & 1.75 & 29.7 & $\begin{array}{l}\text { Boston } \\
\text { Scientific }\end{array}$ & No & No & No & No & No \\
\hline 15 & 83 & M & 95 & 1.78 & 30 & $\begin{array}{l}\text { Boston } \\
\text { Scientific }\end{array}$ & No & Yes & No & No & Yes \\
\hline 16 & 79 & $\mathrm{~F}$ & 79 & 1.68 & 28 & $\begin{array}{l}\text { Boston } \\
\text { Scientific }\end{array}$ & No & No & No & No & Yes \\
\hline 17 & 72 & M & 75 & 1.75 & 24.5 & Medtronic & No & No & No & No & Yes \\
\hline 18 & 80 & $F$ & 63 & 1.60 & 24.6 & $\begin{array}{l}\text { Boston } \\
\text { Scientific }\end{array}$ & No & No & No & No & Yes \\
\hline 19 & 72 & $\mathrm{~F}$ & 66 & 1.52 & 28.6 & Medtronic & $\mathrm{No}$ & No & No & No & Yes \\
\hline 20 & 77 & M & 70 & 1.65 & 25.7 & Medtronic & No & Yes & No & No & Yes \\
\hline
\end{tabular}

Received: 24 November 2015 Accepted: 7 July 2016

Published online: 19 July 2016

\section{References}

1. Mond HG, Proclemer A. The 11th world survey of cardiac pacing and implantable cardioverter-defibrillators: calendar year 2009_a world society of arrhythmia's project. Pace. 2011;34:1013-27.

2. Greenspon AJ, Patel JD, Lau E, Ochoa JA, Frisch DR, Ho RT, Pavri BB, Kurtz SM. Trends in permanent pacemaker implantation in the United States from 1993 to 2009: increasing complexity of patients and procedures. J Am Coll Cardiol. 2012;60(16):1540-5.

3. Kurtz SM, Ochoa JA, Lau E, Shkolnikov Y, Pavri BB, Frisch D, Greenspon AJ. Implantation trends and patient profiles for pacemakers and implantable cardioverter defibrillators in the United States: 1993-2006. Pace. 2010;33:705-11.

4. Apfelbaum JL, Belott P, Connis RT, Nickinovich DG, Rozner MA, Zaidan JR. Practice Advisory for the perioperative management of patients with cardiac implantable electronic devices: pacemakers and implantable cardioverterdefibrillators. An updated report by the american society of anesthesiologists task force on perioperative management of patients with cardiac implantable electronic devices. Anesthesiology. 2011;114(2):247-61.

5. Crossley GH, Poole JE, Rozner MA, Asirvatham SJ, Cheng A, Chung MK, Ferguson J, Gallagher JD, Gold MR, Hoyt RH, Irefin S, Kusumoto FM, Moorman LP, Thompson A. The Heart Rhythm Society (HRS)/American Society of Anesthesiologists (ASA) expert consensus statement on the perioperative management of patients with implantable defibrillators, pacemakers and arrhythmia monitors: facilities and patient management: this document was developed as a joint project with the American Society of Anesthesiologists (ASA), and in collaboration with the American Heart Association (AHA), and the Society of Thoracic Surgeons (STS). Heart Rhythm. 2011;8(7):1114-54.

6. Healey JS, Merchant R, Simpson C, Tang T, Beardsall M, Tung S, Fraser JA, Long L, van Vlymen JM, Manninen P, Ralley F, Venkatraghavan L, Yee R, Prasloski B, Sanatani S, Philippon F. Canadian Cardiovascular Society/Canadian 
Anesthesiologists'Society/Canadian Heart Rhythm Society joint position statement on the perioperative management of patients with implanted pacemakers, defibrillators, and neurostimulating devices. Can J Anesth. 2012;59(4):394-407.

7. Ehrenwerth J, Seifert HA. Electrical and fire safety. In: Barash PG, editor. Clinical Anesthesia. 5th ed. Philadelphia: Lippincott Williams \& Wilkins; 2006. p. 164-6.

8. Shapiro WA, Roizen MF, Singleton MA, Morady F, Bainton CR, Gaynor RL. Intraoperative pacemaker complications. Anesthesiology. 1985;63:319-22.

9. Preisman S, Cheng DC. Life-threatening ventricular dysrhythmias with inadvertent asynchronous temporary pacing after cardiac surgery. Anesthesiology. 1999;91(3):880-3.

10. Ren X, Hongo RH. Polymorphic ventricular tachycardia from R on-T pacing. J Am Coll Cardiol. 2009;53(2):218.

11. Huagui L. Magnet decoration, beautiful but potentially dangerous for patients with implantable pacemakers or defibrillators. Heart Rhythm. 2007:4:5-6.

12. Schulman PM, Rozner MA. Use caution when applying magnets to pacemakers or defibrillators for surgery. Anesth Analg. 2013;117:422-7.

13. Purday JP, Towey RM. Apparent pacemaker failure caused by activation of ventricular threshold test by a magnetic instrument mat during general anaesthesia. Br J Anaesth. 1992;69(6):645-6.

14. Zaphiratos V, Donati F, Drolet P, Bianchi A, Benzaquen B, Lapointe J, Fortier LP. Magnetic interference of cardiac pacemakers from a surgical magnetic drape. Anesth Analg. 2013;116(3):555-9.

15. Ryf S, Wolber T, Duru F, Luechinger R. Interference of neodymium magnets with cardiac pacemakers and implantable cardioverter-defibrillators: an in vitro study. Technol Health Care. 2008;16(1):13-8.

16. Wolber T, Ryf S, Binggeli C, Holzmeister J, Brunckhorst C, Luechinger R, Duru F. Potential interference of small neodymium magnets with cardiac pacemakers and implantable cardioverter-defibrillators. Heart Rhythm. 2007:4:1-4.

17. Beinart R, Guy ML, Ellinor PT. Intermittent, erratic behaviour of an implantable cardioverter defibrillator secondary to a hidden magnetic source of interference. Europace. 2011;13:1508-9.

18. Rasmussen MJ, Friedman PA, Hammill SC, Rea RF. Unintentional deactivation of implantable cardioverter-defibrillators in health care settings. Mayo Clin Proc. 2002;77(8):855-9.

19. Hiller H, Weissberg N, Horowitz G, llan M. The safety of dental mini-magnets in patients with permanent cardiac pacemakers. J Prosthet Dent. 1995;74:420-1.

Submit your next manuscript to BioMed Central and we will help you at every step:

- We accept pre-submission inquiries

- Our selector tool helps you to find the most relevant journal

- We provide round the clock customer support

- Convenient online submission

- Thorough peer review

- Inclusion in PubMed and all major indexing services

- Maximum visibility for your research

Submit your manuscript at www.biomedcentral.com/submit 